\title{
FVDZ Hessen
}

Samstag, 22. April 2017, 9.30 Uhr s.t., im Collegium Glashütten

Kommunikations- und Trainings-Center GmbH, Wüstemser Str. 1, 61479 Glashütten

Der Landesverband lädt laut. $\$ 14$ (Abs. 2, 4 u. 8) der Satzung herzlich ein.

\section{Tagesordnung:}

1. Eröffnung durch den Versammlungsleiter

2. Begrüßung durch den Landesvorsitzenden

3. Grußwort des Bundesvorsitzenden

4. Gastredner: Herr Prof. Dr. Sodan

(Deutsches Institut für Gesundheitsrechte)

Die „Bürgerversicherung“ als Zwangsversicherung und

ihre möglichen Folgen für die medizinische Versorgung

5. Bericht des Landesvorsitzenden

6. Anträge

- Mittagspause -
7. Ehrungen langjähriger Mitglieder

8. Feststellung der Beschlussfähigkeit

9. Bericht der Kassenprüfer

10. Entlastung des Landesvorstandes

11. Haushaltsplan 2017

12. Wahl des Landesvorsitzenden und bis zu zwei Stellvertreter

13. Wahl der Beisitzer im Landesvorstand

14. Wahl des Versammlungsleiters und der beiden Stellvertreter

15. Wahl von zwei weiteren Delegierten und deren Stellvertreter zur Hauptversammlung

16. Wahl von zwei Kassenprüfern und deren Stellvertreter

Anträge gemäß Satzung $\$ 8$ (Abs. 9 und 10) sind bis spätestens zwei Wochen vor der Versammlung dem Landesvorstand über die Landesgeschäftsstelle einzureichen. Die Anträge sind zu begründen.

Mit kollegialen Grüßen,

\section{Hier steht eine Anzeige.}

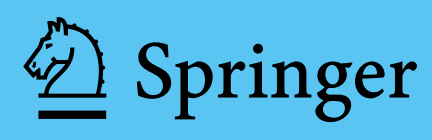

